\title{
Tubercúlide papulonecrótica: um relato de caso
}

\section{Papulonecrotic tuberculids: a case report \\ Tubercúlide papulonecrótica: un informe de caso}

\author{
Lúcio Gomes Rodrigues Alves ${ }^{1}[0$ \\ ${ }^{1}$ Escola Nacional de Saúde Pública (ENSP) - Fiocruz - RJ / Instituto de Desenvolvimento Institucional e Ação Social (IDEIAS)
}

\section{Resumo}

As tubercúlides são reações de hipersensibilidade cutânea aos antígenos do Mycobacterium tuberculosis. Este é o caso de uma mulher de 45 anos que procurou a Unidade Básica de Saúde (UBS) com um quadro de eritema nodoso com mais de 10 anos de evolução, de etiologia desconhecida, e que evoluía como nódulos em pescoço e membros, que se tornavam úlceras necróticas, cicatrizavam e recidivavam periodicamente. Biópsias das lesões evidenciavam um processo inflamatório granulomatoso com extensa necrose, sugestivo de tuberculose, mas sem a presença do bacilo. Após anos sem tratamento adequado, finalmente levantou-se a hipótese de tubercúlide papulonecrótica. A paciente iniciou tratamento com o esquema básico $(2 \mathrm{RHZE} / 4 \mathrm{RH})$ e dessensibilização vacinal, recebendo alta por cura.

Palavras-chave: Tuberculose Cutânea; Hipersensibilidade Tardia; Mycobacterium tuberculosis; Tuberculina.

\begin{abstract}
The tuberculids are cutaneous hypersensitivity reactions to Mycobacterium tuberculosis antigens. This is the case of a 45-year-old woman who sought the Basic Health Unit (BHU) with erythema nodosum with a 10-year evolution, of unknown etiology, that evolved as nodules in the neck and limbs, which became necrotic ulcers, cicatrized and recurred periodically. Biopsies of the lesions revealed a granulomatous inflammatory process with extensive necrosis, suggestive of tuberculosis, but without the presence of the bacillus. After years without adequate treatment, the hypothesis of papulonecrotic tuberculids finally arose. The patient started treatment with the basic regimen $(2 \mathrm{RHZE} / 4 \mathrm{RH})$ and vaccine desensitization, receiving discharge by cure.
\end{abstract}

Keywords: Tuberculosis Cutaneous; Hypersensitivity, Delayed; Mycobacterium tuberculosis; Tuberculin.

\section{Resumen}

Las tubercúlides son reacciones de hipersensibilidad cutánea a los antígenos del Mycobacterium tuberculosis. Este es el caso de una mujer de 45 años que buscó la Unidad Básica de Salud (UBS) con un cuadro de eritema nodoso con más de 10 años de evolución, de etiología desconocida, y que evolucionaba como nódulos en cuello y miembros, que se tornaban úlceras necróticas, cicatrizaban y recidivaban periódicamente. Las biopsias de las lesiones evidenciaban un proceso inflamatorio granulomatoso con una extensa necrosis, sugestiva de tuberculosis, pero sin la presencia del bacilo. Después de años sin tratamiento adecuado, finalmente se levantó la hipótesis de tubercúlide papulonecrótica. La paciente inició tratamiento con el esquema básico (2RHZE / 4RH) y desensibilización vacunal, recibiendo alta por curación.

Palabras clave: Tuberculosis Cutánea; Hipersensibilidad Retardada; Mycobacterium tuberculosis; Tuberculina.

Como citar: Alves LGR.Tubercúlide papulonecrótica: um relato de caso. Rev Bras Med Fam Comunidade. 2020;15(42):1980. https://doi.org/10.5712/rbmfc15(42)1980

\section{Autor correspondente:} Lúcio Gomes Rodrigues Alves E-mail: lucio.alves@globo.com Fonte de financiamento: Não se aplica. Parecer CEP: Não se aplica Procedência: não encomendado Avaliação por pares: externa Recebido em: 15/02/2019. Aprovado em: 13/08/2020. 


\section{INTRODUÇÃO}

A tuberculose é uma doença infecciosa, causada pelo bacilo Mycobacterium tuberculosis, que tipicamente afeta os pulmões e pode atingir qualquer tecido do corpo. Segundo a Organização Mundial da Saúde (OMS), em nível global, estima-se que, em 2017, cerca de 10 milhões de indivíduos tenham desenvolvido tuberculose. O Brasil se encontra entre os 30 países com maior prevalência de tuberculose, os quais respondem por cerca de $87 \%$ do total de casos. ${ }^{1}$

As formas extrapulmonares não representam risco de transmissão e estão associadas à baixa resistência imunológica. Sempre foram raras, com uma prevalência de $10 \%$ entre todos os casos de tuberculose. Porém, após o surgimento da AIDS, a prevalência deu um salto para cerca de $62 \%$, aumentando a importância de seu estudo. A tuberculose cutânea está entre as formas menos comuns e se divide em formas multibacilares, consideradas "formas verdadeiras", formas paucibacilares e formas reativas, que resultam do fenômeno de hipersensibilidade e nas quais não se consegue demonstrar a presença do bacilo. Entre estas últimas, se enquadra a tubercúlide papulonecrótica. ${ }^{2}$

Este artigo relata o caso clínico de uma paciente do sexo feminino, de meia idade, que procurou uma UBS após peregrinar por muitos anos portando uma patologia cutânea ulcerativa, dolorosa e recidivante, de causa desconhecida. A doença obrigou a paciente a se afastar do trabalho e gerava um estigma social.

\section{APRESENTAÇÃO DO CASO}

Mulher de 45 anos procurou a UBS em abril de 2017, relatando que há mais de 10 anos apresentava nódulos subcutâneos em pescoço, braços, mãos e pernas que evoluíam para úlceras necrosadas e deixavam cicatrizes (Figuras 1, 2 e 3).

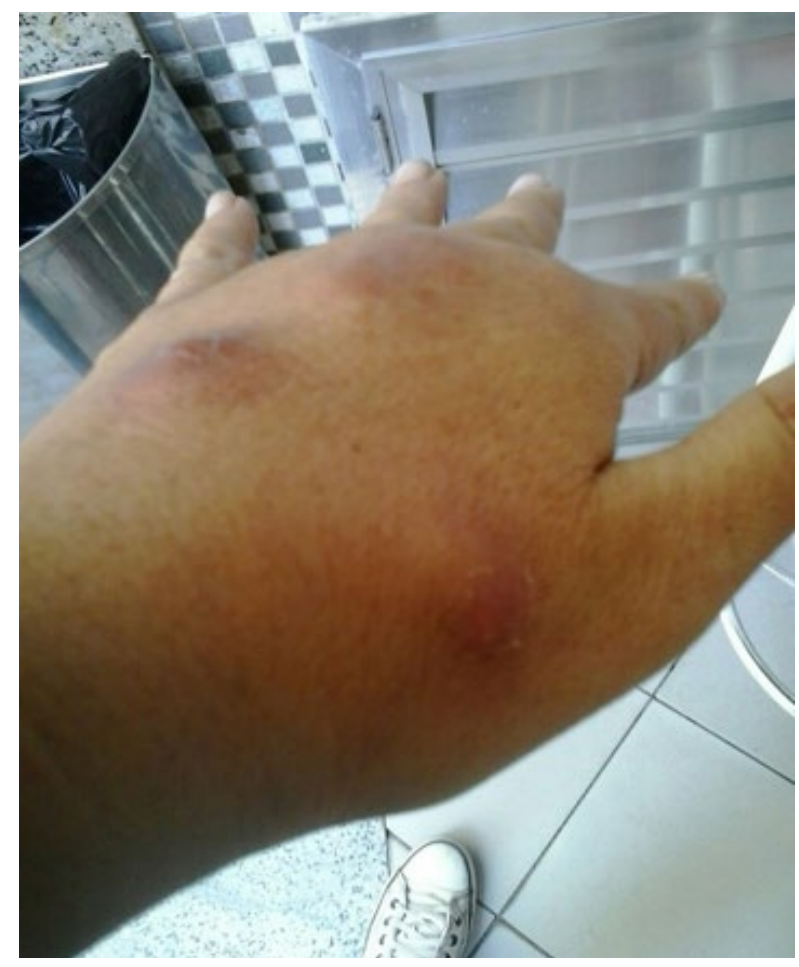

Figura 1. Nódulos subcutâneos em mão. 


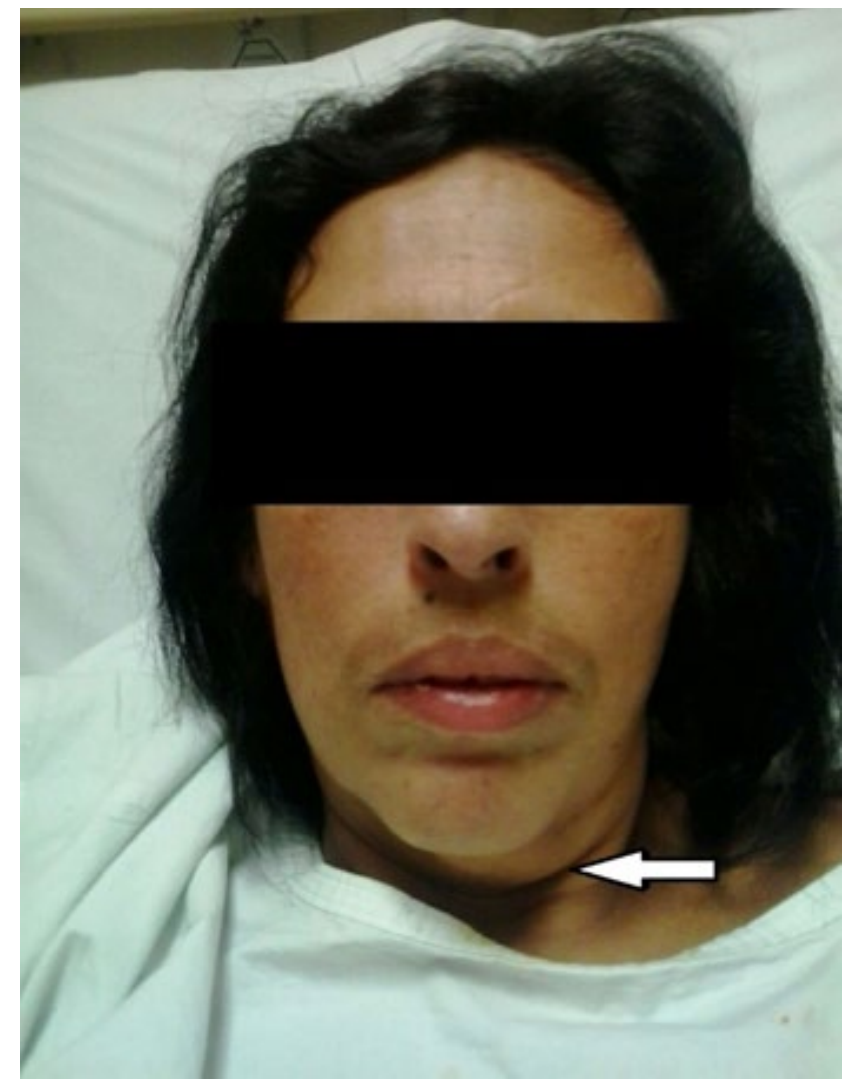

Figura 2. Linfadenomegalia cervical (seta).

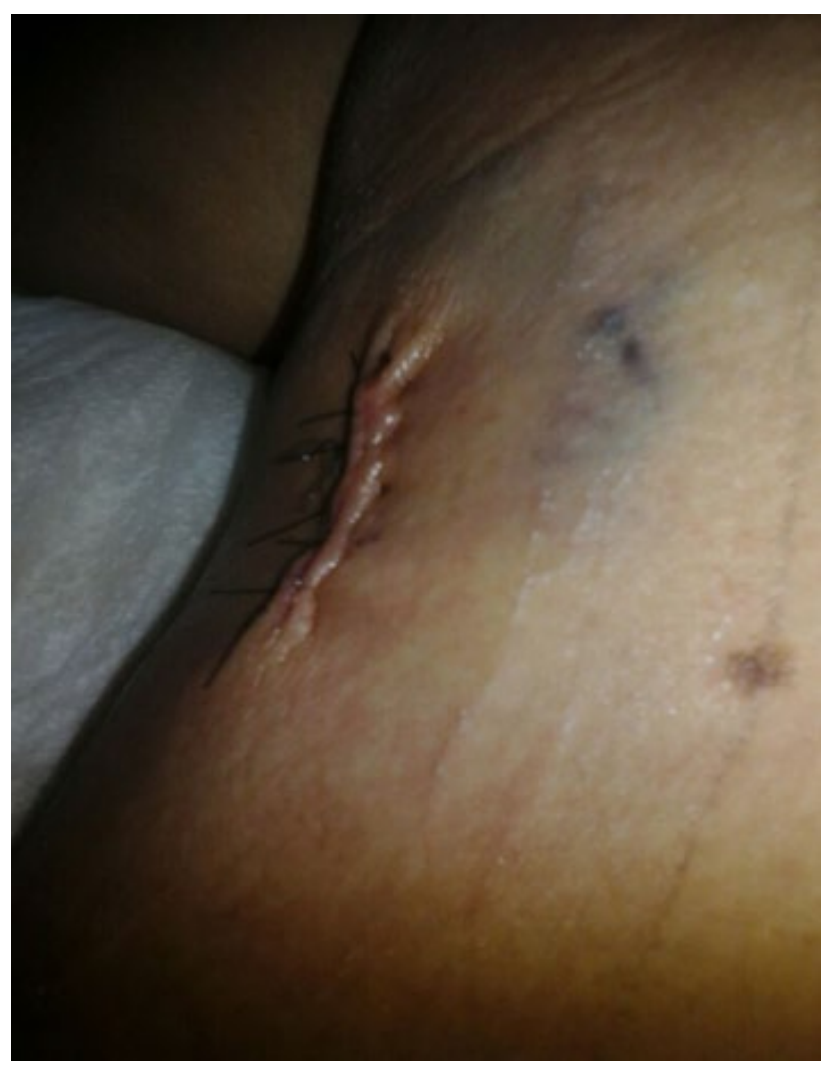

Figura 3. Lesão biopsiada em coxa. 
De tempos em tempos as lesões recidivavam, sem alcançar a cura. Afirmava ter sido diagnosticada como portadora de eritema nodoso, de etiologia desconhecida. A história epidemiológica indicava contato com pacientes de tuberculose, pois trabalhava como técnica de enfermagem, em uma enfermaria de clínica médica, de um hospital privado. Nunca apresentou sintomas sistêmicos típicos da tuberculose, como febre, tosse, perda de peso e sudorese noturna. As lesões eram dolorosas.

Realizou diversas biópsias, cujos laudos sempre apresentavam o mesmo padrão: processo inflamatório granulomatoso com extensa necrose, de padrão similar às lesões de tuberculose cutânea, mas sem a identificação do M. tuberculosis, tanto pela técnica de Ziehl-Neelsen quanto pela cultura. Apresentava prova da tuberculina positiva, com resultado de $25 \mathrm{~mm}$; exames de escarro (pesquisa de BAAR) sempre foram negativos; uma tomografia computadorizada de tórax, de 2016, evidenciava "estrias densas irregulares de aspecto residual no segmento superior do lobo inferior esquerdo".

Pelo quadro dermatológico, foi afastada do trabalho por licença médica. Nos últimos dois anos percebeu que o quadro vinha se agravando, quando resolveu procurar um infectologista da rede privada, o qual, finalmente, diagnosticou como uma tubercúlide papulonecrótica, encaminhando a paciente para a UBS mais próxima de sua residência para iniciar o esquema básico para tuberculose e dessensibilização por vacina de tuberculina.

Em nossa unidade, após a anamnese e exame físico, tomamos a iniciativa de estabelecer contato com nossos coordenadores, visto que desconhecíamos a referida patologia. Tínhamos dúvida se deveríamos notificá-la como um caso novo, iniciando o tratamento usual, ou encaminhá-la a um imunologista de referência. Afinal, a paciente não era bacilífera e a etiologia parecia ser imunológica. Será que o tratamento deveria ser mesmo pela quimioterapia antituberculosa? Após meia hora de espera, recebemos a orientação de que o caso deveria ser notificado como tuberculose cutânea, e que deveríamos, sim, fazer uso do esquema básico. Também fomos orientados a encaminhá-la para a avaliação de um pneumologista. Realizamos ainda o teste rápido para HIV, que foi negativo.

Assim procedendo, realizamos o tratamento supervisionado do esquema básico: rifampicina 150mg + isoniazida $75 \mathrm{mg}$ + pirazinamida $400 \mathrm{mg}$ + etambutol $275 \mathrm{mg}$ - 4 comprimidos (comp.) ao dia por 2 meses, seguindo-se rifampicina 150mg + isoniazida 75mg - 4 comp. ao dia por 4 meses, ${ }^{3,4}$ com início em 24/04/2017. Concomitantemente, a paciente iniciou a dessensibilização, com vacina de tuberculina, em uma clínica de alergia da rede privada.

Em dois meses já apresentava redução dos nódulos e do processo inflamatório. Retornou com a avaliação da pneumologista, confirmando que deveríamos seguir com a conduta atual. Avaliamos os contactantes e todos eram saudáveis e receberam alta. O tratamento se encerrou em outubro de 2017 e todos os nódulos haviam sumido. Recebeu alta por cura e foi considerada apta para retornar ao trabalho.

\section{DISCUSSÃO}

As tubercúlides são consideradas reações de hipersensibilidade à tuberculina, proteína derivada do $M$. tuberculosis, embora alguns relatos também mencionem associação com $M$. bovis ${ }^{5}$ e complexo M. avium. ${ }^{6}$ A patogênese exata ainda é desconhecida, contudo a hipótese mais aceita propõe uma reação de hipersensibilidade tardia, do tipo IV. Alguns autores defendem que o processo, inicialmente, 
envolveria também uma reação do tipo III, na qual o indivíduo imunocompetente produziria anticorpos, formando imunocomplexos com a tuberculina, que viajaria pela corrente sanguínea até os pequenos vasos da pele, onde ocorreria a reação tardia. ${ }^{3,4}$ São doenças relativamente raras, mesmo em países onde a tuberculose é endêmica. Os casos de tuberculose cutânea, incluindo as tubercúlides, correspondem a $0,15 \%$ de todos os casos de tuberculose e $1 \%$ dos casos de tuberculose extrapulmonar. ${ }^{7}$ Tradicionalmente são classificadas como uma forma de tuberculose extrapulmonar, embora os especialistas se dividam em duas correntes: uma que considera as tubercúlides como meras formas de apresentação cutânea da tuberculose, indicando o tratamento apenas com a quimioterapia usual; e, a outra, minoritária, que aceita a teoria de que seriam reações alérgicas à tuberculina, defendendo o uso da vacina como coadjuvante. ${ }^{8}$

Existem três tipos de tubercúlides: eritema indurado de Bazin, lichen scrofulosorum e tubercúlide papulonecrótica. ${ }^{7-9}$ Segundo Degitz (1997), ${ }^{10}$ a ausência do bacilo da tuberculose em lesões de pele, tanto na bacterioscopia como na cultura, "foi percebida por Darier em 1896, que propôs chamar estas alterações na pele de tubercúlides". ${ }^{10}$

A tubercúlide papulonecrótica se caracteriza por pápulas ou nódulos, dolorosos, especialmente nos membros, com tendência simétrica, que ulceram e necrosam, evoluindo em ciclos de remissões e recidivas, deixando cicatrizes. ${ }^{7-9} \dot{E}$ mais frequente em crianças e adultos jovens, e há um predomínio do sexo feminino na razão de 2:1. ${ }^{8}$ Normalmente não há sintomas sistêmicos, como febre, sudorese noturna e perda de peso. A prova da tuberculina costuma ser forte reatora e não se isola o bacilo nas lesões, embora se possa evidenciar o seu DNA pela reação em cadeia da polimerase (PCR). ${ }^{8} \mathrm{~A}$ histopatologia indica necrose da derme, infiltrado granulomatoso malformado, vasculite, edema esponjoso perivascular e necrose folicular ou supuração. ${ }^{11}$

As outras duas formas de tubercúlides se diferenciam pelas faixas etárias atingidas e/ou características das lesões. O eritema indurado de Bazin geralmente se apresenta como nódulos que sofrem erupções ulcerativas, com distribuição simétrica nas panturrilhas, e predileção por mulheres de meia idade. Já o lichen scrofulosorum se caracteriza por pápulas perifoliculares agrupadas ou lesões anulares, de cor avermelhada, amarelada ou marrom, afetando o tronco. Contudo todas têm em comum a ausência do bacilo de Koch nas lesões, tanto por microscopia como pela cultura, e os pacientes geralmente apresentam-se bem e saudáveis. ${ }^{7}$

Em nossa revisão da literatura, identificamos 37 artigos que relatam casos de tubercúlide papulonecrótica. Dentre estes, devemos destacar 11 relatos que apontaram o acometimento dramático da genitália ( 1 caso da vulva ${ }^{12}$ e 10 do pênis), sendo o câncer de pênis a patologia mais importante no diagnóstico diferencial. ${ }^{13}$ Outro fato relevante é que, entre todos os trabalhos, de 1958 a 2017, apenas um, publicado no Japão, em 1989, por Nakamura et al., ${ }^{14}$ fez uso da dessensibilização vacinal, em associação com os tuberculostáticos, evidenciando que pouquíssimos médicos consideram importante o uso da vacina.

Para estabelecermos o diagnóstico de uma verdadeira tubercúlide, as lesões de pele devem preencher todos os critérios maiores e a maioria dos critérios menores, conforme listado na Tabela 1.7 
Tabela 1. Critérios maiores e menores para o diagnóstico das tubercúlides.

\begin{tabular}{ll}
\hline & - evidência histológica de inflamação granulomatosa tuberculosa nas biópsias das lesões de pele; \\
& - ausência de evidências do bacilo Mycobacterium em bacterioscopia e culturas destas lesões, ou em investigações \\
Critérios maiores & complementares como RX, lavado gástrico, primeira urina da manhã, inoculação de secreção das lesões em cobaias; \\
& - teste da tuberculina geralmente reator forte; \\
& - boa resposta ao esquema quimioterápico básico com resolução total das lesões e sem recidiva. \\
\hline Critérios menores & - paciente geralmente com boa saúde e com alto grau de imunidade à tuberculose; \\
& - erupções de pele geralmente simétricas; \\
\hline
\end{tabular}

Fonte: Chan (2000). ${ }^{7}$

Portanto, a tubercúlide papulonecrótica é de difícil diagnóstico, não só por ser rara, mas pela ausência de sintomas sistêmicos, pela ausência dos bacilos nas lesões e pelo comportamento em ciclos de remissão e recidiva, podendo levar anos até o diagnóstico correto.

Infelizmente, o atual Manual de Recomendações para o Controle da Tuberculose no Brasil, ${ }^{3}$ do Ministério da Saúde, não faz qualquer menção à tuberculose cutânea, muito menos às tubercúlides, dificultando o diagnóstico para o profissional de saúde da atenção básica, embora exista um guia de "Dermatologia na Atenção Básica”, de 2002, que menciona as tubercúlides de forma resumida e confusa, citando apenas o eritema indurado de Bazin. ${ }^{15}$

O tratamento deve seguir o protocolo usual de um caso novo de tuberculose, respeitando o esquema básico de seis meses, podendo ter como coadjuvante a dessensibilização vacinal, de acordo com a Tabela $2 .{ }^{16}$ É importante destacar que a manipulação da tuberculina deve ser feita por profissionais de saúde capacitados e com técnica rigorosamente estéril, em ambiente adequado. No âmbito do Sistema Único de Saúde (SUS), as UBS estão preparadas, visto que a imunização em salas de vacinas é praticamente universal.

A dessensibilização vacinal deve ser prescrita, preferencialmente, por um alergoimunologista, no nível secundário, e as aplicações podem ser mantidas na UBS. O tratamento tem periodicidade semanal e pode durar de quatro a seis meses. No nosso caso, o tratamento logrou êxito rapidamente, em conformidade com todos os relatos da literatura, vindo a paciente a recuperar sua autoestima e capacidade laboral.

Tabela 2. Preparo de vacinas de dessensibilização

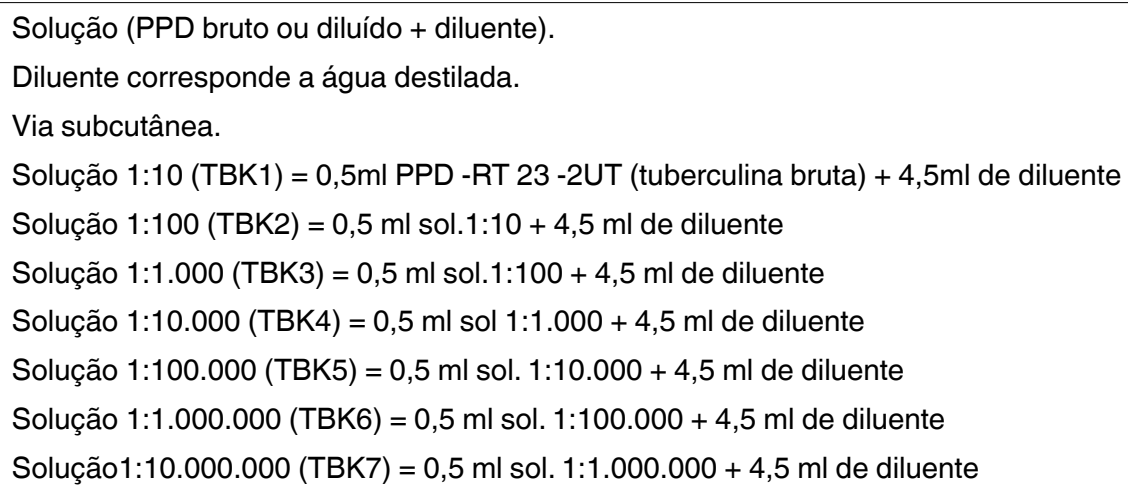




\section{REFERÊNCIAS}

1. World Health Organization (WHO). Global tuberculosis report 2018 [Internet]. Geneva:WHO; 2018; [acesso em 2019 Fev 02]. Disponível em: https://apps.who.int/iris/bitstream/handle/10665/274453/9789241565646-eng.pdf

2. Capone D, Mogami R, Lopes AJ, Tessarollo B, Cunha DL, Capone RB, et al. Tuberculose extrapulmonar. Rev HUPE [Internet]. 2006; [citado 2019 Fev 02]; 5(2):54-67. Disponível em: https://www.e-publicacoes.uerj.br/index.php/revistahupe/article/view/9210

3. Ministério da Saúde (BR). Secretaria de Vigilância em Saúde. Departamento de Vigilância Epidemiológica. Manual de recomendações para o controle da tuberculose no Brasil [Internet]. Brasília (DF): Ministério da Saúde; 2011; [acesso em 2019 Fev 11]. Disponível em: http://bvsms.saude.gov.br/bvs/publicacoes/manual_recomendacoes_controle_tuberculose_brasil.pdf

4. Dalcolmo MP. Tratamento da tuberculose sensível e resistente. Pulmão RJ [Internet]. 2012; [citado 2019 02 05]; 21(1):55-9. Disponível em: http://www.sopterj.com.br/wp-content/themes/_sopterj_redesign_2017/_revista/2012/n_01/13.pdf

5. Iden DL, Rogers RS, Schroeter. Papulonecrotic tuberculid secondary to Mycobacterium bovis. Arch Dermatol. 1978 Abr;114(4):564-6. DOI: https://doi.org/10.1001/archderm.114.4.564

6. Williams JT, Pulitzer DR, DeVillez RL. Papulonecrotic tuberculid secondary to disseminated Mycobacterium avium complex. Int J Dermatol. 1994 Fev;33(2):109-12. DOI: https://doi.org/10.1111/j.1365-4362.1994.tb01537.x

7. Chan KT. Tuberculide - a clinical and epidemiological review. Hong Kong Dermatol Venereol Bull [Internet]. 2000 Mar; [citado 201902 03]; 8(1):9-15. Disponível em: http://medcomhk.com/hkdvb/pdf/200003-03.pdf

8. Pereira JCB. Análise comparativa entre tuberculides e tuberculose extrapulmonar - uma outra face do Mycobacterium tuberculosis. Rev Port Pneumol [Internet]. 2008 Mai/Jun; [citado 201902 03]; 14(3):391-407. Disponível em: https:/www.sciencedirect.com/science/article/ pii/S0873215915302464/pdf?md5=740cea1a699e3f489615f6f3973c1b8b\&pid=1-s2.0-S0873215915302464-main.pdf\&_valck=1

9. Bolognia JF, Jorizzo JL, Schaffer JV. Tubercúlides. In: Dermatologia. 3르 ed. Rio de Janeiro: Elsevier; 2015. p. $1230-32$.

10. Degitz K. Das Konzept der Tuberkulide. In: Plewig G, Przybilla B, eds. Fortschritte der praktischen Dermatologie und Venerologie. Berlin, Heidelberg: Springer; 1997. v. 15. DOI: https://doi.org/10.1007/978-3-642-60534-5_35

11. Jordaan HF, Van Niekerk DJ, Louw M. Papulonecrotic tuberculid. A clinical, histopathological, and immunohistochemical study of 15 patients. Am J Dermatopathol. 1994 Oct;16(5):474-85. PMID: 7802163 DOI: https://doi.org/10.1097/00000372-199410000-00002

12. Wong S, Rizvi H, Cerio R, O'Toole EA. An unusual case of vulval papulonecrotic tuberculid. Clin Exp Dermatol. 2010;36(3):277-80. DOI: https://doi.org/10.1111/j.1365-2230.2010.03925.x PMID: 21418269 DOI: https://doi.org/10.1111/j.1365-2230.2010.03925.x

13. Stevanovic OV. Papulonecrotic tuberculids of glans penis. AMA Arch Derm. 1958;78(6):760-1. DOI: https://doi.org/10.1001/ archderm.1958.01560120080014 DOI: https://doi.org/10.1001/archderm.1958.01560120080014

14. Nakamura S, Aoki M, Nakayama K, Kanamori S, Onda S. Penis tuberculid (papulonecrotic tuberculid of the glans penis): treatment with a combination of rifampicin and an extract from tubercle bacilli (T.B. Vaccine). J Dermatol. 1989 Abr;16(2):150-3. DOI: https://doi. org/10.1111/j.1346-8138.1989.tb01238.x DOI: https://doi.org/10.1111/j.1346-8138.1989.tb01238.x

15. Ministério da Saúde (BR). Secretaria de Políticas de Saúde. Departamento de Atenção Básica. Dermatologia na Atenção Básica. Cadernos de Atenção Básica no 9. Série A - Normas de Manuais Técnicos - 1ae edição. Brasília (DF): Ministério da Saúde; 2002. Disponível em: http://bvsms.saude.gov.br/bvs/publicacoes/guiafinal9.pdf

16. Pereira JCB. Quando devemos utilizar a dessensibilização tuberculínica. Pulmão RJ [Internet].2005 Jul/Set; [citado 2019 02 11]; 14(3):23741. Disponível em: http://www.sopterj.com.br/wpcontent/themes/_sopterj_redesign_2017/_revista/2005/n_03/08.pdf 